\title{
Typhlodromips swirskii (Athias- Henriot) as a biological control agent for Panonychus citri (McGregor) (Phytoseiidae, Tetranychidae)
}

\author{
M. M. E. Elmoghazy \\ Agric. Zoology and Nematology Dept., Fac. of Agric., Alazhar Univ., Cairo, Egypt, \\ e-Mail: drelmoghazy@yahoo.com \\ (Received: March 10, 2010)
}

\begin{abstract}
Typhlodromips swirskii was able to develop and reproduce when fed on Panonychus citri. Temperature negatively

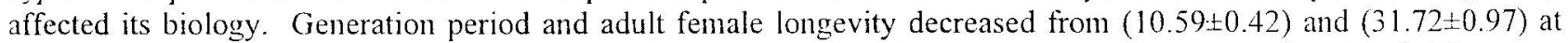
$20^{\circ} \mathrm{C}$. to $(7.81 \pm 0.40)$ and $(21.72 \pm 0.41)$ days at $30^{\circ} \mathrm{C}$. respectively. Also female laid an average of $(33.75 \pm 2.64)$ eggs at $20^{\circ} \mathrm{C}$., decreased to $(24.19 \pm 1.72)$ days at $30^{\circ} \mathrm{C}$. However, $\mathrm{r}_{\mathrm{m}}$ was 0.14 and 0.18 at both degrees respectively. $T$. swirskii proved to be effective predator for $P$. citri, as at high level of eight predators/ orange seedling, Citrus anrantium L., it gave the highest percent reduction from $27.27 \%$ after a five days to $88.89 \%$ after a month from release.
\end{abstract}

Key Words: Typhlodromips swirskii, Biological control, Panonychus citri.

\section{INTRODUCTION}

Predaceous plytoseiid mites are important natural enemies of several phytophagous mites and other pests on various crops. Typhlodromips swirskii (Athias-Henriot) became commercially available in 2005 and is used in Europe as a control agent for whiteflies and thrips (Gerson and Weintraub, 2007). Compatibility of Typhlodromips swirskii and Orius insidiosus for biological control of Frankliniella occidentalis on roses has been reported by Chow et al., (2010).

The citrus red mite, Panonychus citri (McGregor) has a worldwide distribution and is noted on over 80 species of host plants, including citrus (Bolland et al., 1998 and Zhang. 2003). Serious infestation by $P$. citri can cause heavy defoliation and fruit drop (Jeppson et al., 1975 and Emmanouel \& Papadoulis, 1987). It has recently gained economic pest status on citrus in the East Mediterranean region and Turkey (Uygun et cl.. 1992; Karaca. 1994; Kasap ct cl., 1998 and Kasap, 2001). Most of the recent research on biological control of tetranychids, including $P$. citri, has been focused on the family Phytoseiidae, due to their contribution in maintaining prey populations at low densities (McMurtry and Croft, 1997).

Typhlodrompis swirskii (Athias-Henriot) and Panonychus sp. was recorded on citrus leaves in Egypt, Dakahleia governorate, subsequent biological studies revealed that the predator $T$. swirskii fed on immature stages of prey Panonychus sp. under favorable laboratory conditions (Elmoghazy, 2006).

Therefore, this work included biological studies of $T$. swirskii when fed on $P$. citri at 20 and $30^{\circ} \mathrm{C}$. as well as its influence when released at different levels, in suppressing population of P. citri infesting citrus seedlings, Citrus aurantium $\mathrm{L}$.

\section{MATERIALS AND METHODS}

\section{Mite cultures}

T. swirskii stock culture was maintained on $P$. citri, as prey, on sour orange leaves in a controlled rearing room $(25 \pm 2 \circ, 65 \pm 5 \% \mathrm{R}$. H. and 16: $8 \mathrm{~L}:$ D). Both species were collected from sour orange trees, Citrus currantium $\mathrm{L}$.

Thirty discs of fresh citrus leaves $(3 \mathrm{~cm}$. diameter) were placed on wet cotton placed in foildishes $(20 \mathrm{~cm}$. in diameter and $2 \mathrm{~cm}$. deep). Every foil-dish contained six discs of citrus leaves, each disc was surrounded with wet cotton as barrier to prevent mite escape. Newly deposited eggs were transferred singly from stock culture of predator mite to these discs and also immature stages of $P$. citri were transferred from stock culture as prey.

The rearing dises were checked twice daily and the numbers of consumed preys were recorded and replaced by new ones all over the predator life span. The rearing experiment was carried out at 20 and $30 \pm 2{ }^{\circ} \mathrm{C}$. and $65 \pm 5 \%$ R.H. in laboratory, and observations were undertaken twice daily.

\section{Release technique}

Experiment took place from end of May till end of July. Pots planted with citrus seedlings, Citrus aurantium L., of $100 \mathrm{~cm}$. height were put in 4 separate groups under field condition and each group was surrounded by a belt of 2 meters distance. Every seedling was infested with about $50 \mathrm{P}$. cirri individuals and left till infestation averaged 
2-3 mites individuals per leaf. Then, the predator was released in three densities by $4,6,8$ females per seedling. To assess $P$. citri populations, 6 leaves from each level (top, middle and bottom) from 5 seedlings per group (treatment) were randomly chosen and examined on the seedlings every five days throughout a month.

\section{Data analyses}

The numerical data collected were computerized by using SPSS program (Statistical Package of Social Science) program, version 13, 2004 and Henderson \& Teilton formula (1955). They were presented as mean value and standard deviation.

\section{Life table parameters}

Developmental period of different stages and sex ratio of $T$. swirskii progeny were determined and oviposition was recorded daily for each female. Life table parameters were estimated using the life 48, BASIC computer program (Abu-Setta et al., 1986).

\section{RESULTS AND DISCUSSION}

Temperature negatively affected the developmental duration of $T$. swirskii different stages as it decreased when temperature increased from $20^{\circ} \mathrm{C}$. to $30 \pm 2^{\circ} \mathrm{C}$. when fed on $P$. citri.

Table (1) showed that at 20 and $30^{\circ} \mathrm{C}$. the duration of male total immature stages of $T$. swirskii averaged $(6.25 \pm 0.42)$ and $(4.58 \pm 0.20)$ days, while averaged $(6.63 \pm 0.43)$ and $(4.72 \pm 0.26)$ days for female respectively. The male life cycle lasted $(8.50 \pm 0.45)$ and $(6.67 \pm 0.26)$ days, and that of female lasted (9.01 \pm 0.48$)$ and $(6.91 \pm 0.33)$ days. Generation period averaged $(10.59 \pm 0.42)$ and $(7.81 \pm 0.40)$ days at both temperature degrees respectively. Female longevity lasted $(31.72 \pm 0.97)$ and $(21.72 \pm 0.41)$ days respectively.

Table (1): Developmental duration of predatory mite Typhlodromips swirskii fed on Panonychus citri at 20 and $30 \pm 2{ }^{\circ} \mathrm{C}$. and $65 \pm 5 \%$ R.H.

\begin{tabular}{|c|c|c|c|}
\hline \multirow{2}{*}{ Stage } & \multirow{2}{*}{ Sex ${ }^{\circ}$} & \multicolumn{2}{|c|}{ Duration (days) } \\
\hline & & $20^{\circ} \mathrm{C}$ & $30^{\circ} \mathrm{C}$ \\
\hline \multirow{2}{*}{ Total immatures } & $\partial$ & $6.25 \pm 0.42$ & $4.58=0.20$ \\
\hline & q & $6.63 \pm 0.43$ & $4.72=0.26$ \\
\hline \multirow{2}{*}{ Life cycle } & 3 & $8.50 \pm 0.45$ & $6.67=0.26$ \\
\hline & 웅 & $9.01 \pm 0.48$ & $6.91=0.33$ \\
\hline Generation period & $q$ & $10.59 \pm 0.42$ & $7.81=0.40$ \\
\hline \multirow{2}{*}{ Longevity } & 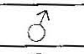 & $26.33 \pm 0.82$ & $16.50=055$ \\
\hline & Q & $31.72 \pm 0.97$ & $21-2=0+1$ \\
\hline \multirow{2}{*}{ Life span } & $\hat{\theta}$ & $34.67 \pm 0.98$ & $231^{-}=0+1$ \\
\hline & q & $40.72=0.93$ & $28.63=09^{7}$ \\
\hline
\end{tabular}

Statistical analysis of the obtained results revealed the occurrence of significant differences between male and female developmental duration periods.

Data presented in table (2) showed that the number of eggs and the daily rate produced by adult female were affected by temperature.

Table (2): Adult female longevity and fecundity of Typhlodromips swirskii fed on Panonychus citri at $20,30 \pm 2{ }^{\circ} \mathrm{C}$. and $65 \pm 5 \% \mathrm{R}$. H.

\begin{tabular}{|c|c|c|c|}
\hline \multicolumn{2}{|c|}{ Parameters } & $20^{\circ} \mathrm{C}$. & $30^{\circ} \mathrm{C}$ \\
\hline \multirow{4}{*}{$\begin{array}{c}\text { Average } \\
\text { periods } \\
\text { (days) }\end{array}$} & Pre-oviposition & $1.59 \pm 0.42$ & $1.03 \pm 0.22$ \\
\hline & Oviposition & $27.63 \pm 0.96$ & $19.19 \pm 0.98$ \\
\hline & Post-oviposition & $2.50 \pm 0.52$ & $1.44 \pm 0.44$ \\
\hline & Longevity & $31.72 \pm 0.97$ & $21.72 \pm 0.41$ \\
\hline \multicolumn{2}{|c|}{ No. of eggs Total average } & $33.75 \pm 2.64$ & $24.19 \pm 1.72$ \\
\hline / female & Daily rate & $1.22 \pm 0.09$ & $1.26 \pm 0.04$ \\
\hline
\end{tabular}

The present results coincided with those obtained by (Zhang, 2003) who recorded a shorter developmental time at high temperature. Kasap and Lu (2004) found that In general, the development duration, preoviposition and postoviposition periods of Euseius scutalis (A. H.) fed on P. citri were shortened as temperature increased.

Data presented in table (3) and Figs. (1,2) clearly showed that sex ratio was not affected by increasing temperature. Therefore, according to life table parameters, the temperature obviously affected the intrinsic rate of increase $\left(\mathrm{r}_{\mathrm{m}}\right)$ of $T$. swirskii as it was 0.14 at $20^{\circ} \mathrm{C}$ and increased to 0.18 individual/female/day at $30^{\circ} \mathrm{C}$. These values were subsequently used to calculate the specific rate of fecundity $(\mathrm{Mx})$ and survival rate curves $(\mathrm{Lx})$ of $T$. swirskii.

Table (3): Effect of temperature on life table parameters of Typhlodromips swirskii when feed on Panonychus citri.

\begin{tabular}{lcc}
\hline \multicolumn{1}{c}{ Parameters } & $20^{\circ} \mathrm{C}$. & $30^{\circ} \mathrm{C}$ \\
\hline Net reproductive rate $\left(\mathrm{R}_{\mathrm{O}}\right)$ & 17.73 & 12.74 \\
\hline Generation time $(\mathrm{T})$ & 19.33 & 14.13 \\
\hline Intrinsic rate of increase $\left(\mathrm{r}_{\mathrm{m}}\right)$ & 0.14 & 0.18 \\
\hline Finite rate of increase $\left(\mathrm{exp}_{\mathrm{rm}}\right)$ & 1.16 & 1.19 \\
\hline Sex ratio (female/total) & 0.72 & 0.72 \\
\hline
\end{tabular}




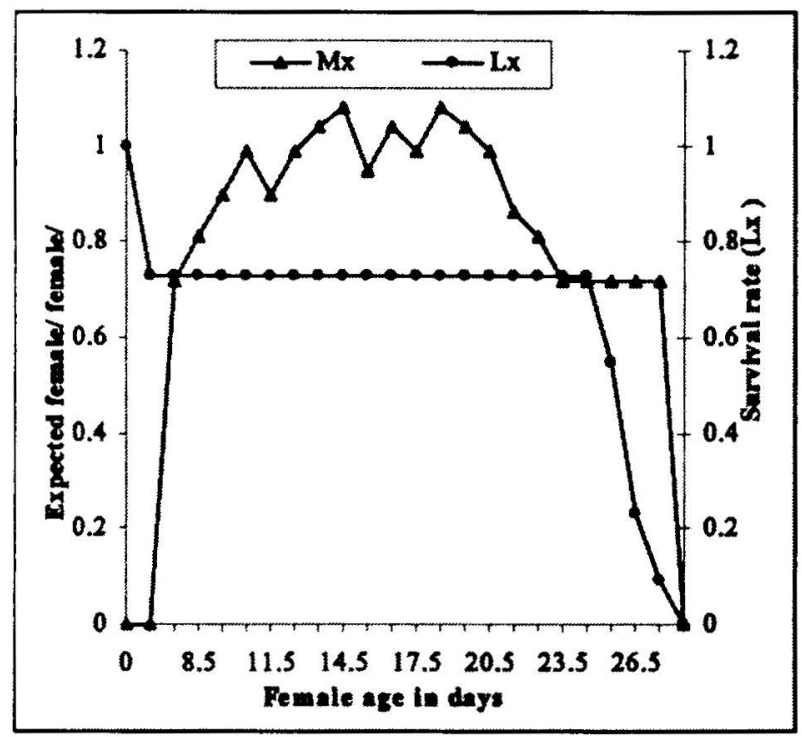

Fig. (1): Natality and survivorship of Typhlodromips swirskii individaually fed on Panonychus citri at $20 \pm 2{ }^{\circ} \mathrm{C}$. and $65 \pm 5 \%$ R.h.

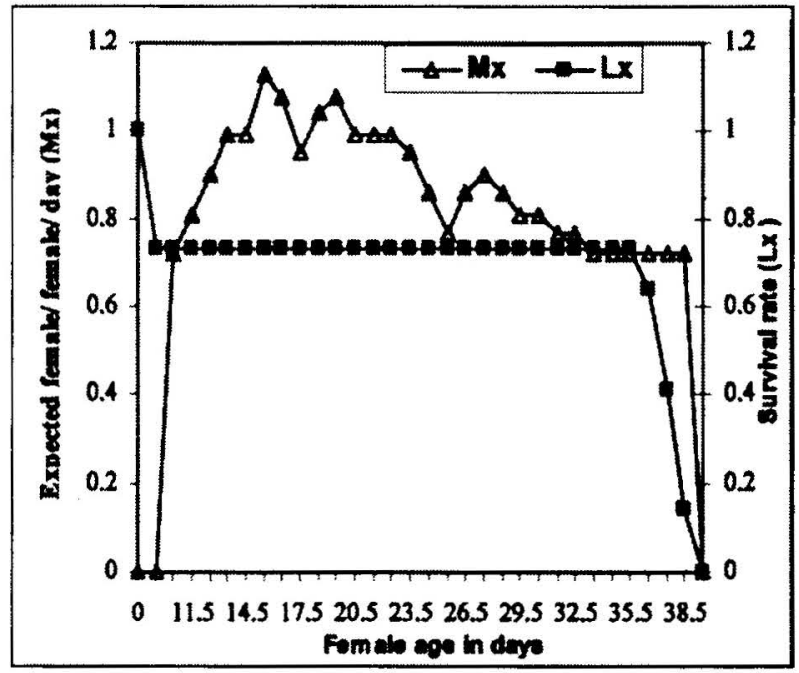

Fig. (2): Natality and survivorship of Typhlodromips swirskii individaually fed on Panonychus citri at $30 \pm 2{ }^{\circ} \mathrm{C}$. and $65 \pm 5 \%$ R.h.

Nomikou et al., (2001, 2002) reported that $\mathrm{r}_{\mathrm{m}}$ of E. scutalis fed on $P$. citri averaged 0.23-0.29 according to the temperature. Kasap and $\mathrm{Lu}$ (2004) found that $\mathrm{r}_{\mathrm{m}}$ value of E. scutalis fed on $P$. citri was lower than the previous one where it averaged between 0.16 and increased to 0.29 (female/female/day) by increasing temperature.

The influence of $T$. swirskii released at three levels on $P$. citri infesting citrus seedling, Citrus aurantium $\mathrm{L}$. under field conditions

Data presented in Table (4) revealed that $T$. swirskii provided effective control of $P$. citri as the average number of its survival moving stages reached its lowest values in treatment $(C=8$ predators/plant at release) which contained the highest number of predators.

Table (4): Average number of moving stages of Panonychus citri survived after Typhlodromips swirskii release.

\begin{tabular}{ccccc}
\hline \multirow{2}{*}{$\begin{array}{c}\text { Days after } \\
\text { release }\end{array}$} & \multicolumn{4}{c}{ Moving stages of Panonychus citri } \\
\cline { 2 - 5 } & $\mathrm{A}$ & $\mathrm{B}$ & $\mathrm{C}$ & Control \\
\hline 5 & $60.4 \pm 2.23$ & $53.8 \pm 2.29$ & $48.2 \pm 2.12$ & $66.0 \pm 2.12$ \\
\hline 10 & $72.2 \pm 1.89$ & $66.2 \pm 2.13$ & $54.0 \pm 1.41$ & $83.8 \pm 2.29$ \\
\hline 15 & $90.2 \pm 1.67$ & $84.0 \pm 2.28$ & $59.8 \pm 2.29$ & $108.2 \pm 3.54$ \\
\hline 20 & $83.8 \pm 1.18$ & $72.2 \pm 2.03$ & $42.2 \pm 2.01$ & $138.0 \pm 4.30$ \\
\hline 25 & $78.2 \pm 2.21$ & $60.0 \pm 2.50$ & $29.8 \pm 2.01$ & $149.8 \pm 4.62$ \\
\hline 30 & $71.8 \pm 1.40$ & $41.8 \pm 1.77$ & $18.2 \pm 1.43$ & $162.0 \pm 4.05$ \\
\hline $\mathrm{A}=4, \quad \mathrm{~B}=6$ and $\mathrm{C}=8$ female predators/plant \\
control $=$ without predator/plant
\end{tabular}

Consequently, data presented in table (5) showed that the highest level of ( 8 predators/plant) enhanced the highest total reduction percentages from $27.27 \%$ after five days to $88.89 \%$ after a month.

Table (5): Reduction Percentage (\%) of Panonychus citri population infesting citrus plants after releasing different levels of Typhlodromips swirskii.

\begin{tabular}{ccccccc}
\hline $\begin{array}{c}\text { Predatory } \\
\text { levels }\end{array}$ & \multicolumn{6}{c}{ Time after release(days) } \\
\cline { 2 - 7 } & 5 & 10 & 15 & 20 & 25 & 30 \\
\hline $\mathrm{A}$ & 9.1 & 14.28 & 16.67 & 39.13 & 48.0 & 55.56 \\
\hline $\mathrm{B}$ & 18.18 & 21.43 & 22.22 & 47.82 & 60.01 & 74.07 \\
\hline $\mathrm{C}$ & 27.27 & 35.71 & 44.44 & 69.56 & 80.01 & 88.89 \\
\hline $\mathrm{A}=4$, & $\mathrm{B}=6$ and & $\mathrm{C}=8$ female predators/plant
\end{tabular}

T. swirskii has been studied for many years as predator of spider mites and citrus pests in Egypt where it naturally occurs (El-Ltaithy and foully 1992).

Thus, it can be concluded that $T$. swirskii is expected to play a considerable role in the biological control of $P$. citri in citrus orchards.

\section{REFERENCES}

Abou-Setta, M. M., Sorrell, R. W. and Childers, C. C., 1986. Life 48: A BASIC computer program to calculate life table parameters for an insect or mite species. Florida Ent. 69(4): 690 - 697.

Bolland, H. R., Gutierrez, J., and Flechtmann, C. H. W., 1998. World catalogue of the spider mite family (Acari: Tetranychidae). Leiden, Brill. 392 pp. 
Chow, A., Chau, A. and Heinz, K. M., 2010. Compatibility of Amblyseizs (Typhlodromips) swirskii (Athias-Henriot) (Acari: Phytoseiidae) and Orius insidiosus (Hemiptera: Anthocoridae) for biological control of Frankliniella occidentalis (Thysanoptera: Thripidae) on roses. Biological Control, 54: 1-9.

El-Latithy, A. Y. M. and Fouly, A. H., 1992. Life table parameters of the two phytoseiid predators Amblyseius scutalis (Athias- Henriot) and $A$. swirskii (A. - H.) (Acari: Phytoseiidae) in Egypt. Journal of Applied Entomology, 113: 8-12.

Elmoghazy, M. M. E.. 2006. Ecological, taxonomical and biological studies on some economic mites. Ph. D. Thesis, Faculty of Agriculture, Alazhar University, 206 pp.

Emmanouel, N.G. and Papadoulis, G. Th., 1987. Panonychus citri (McGregor) (Acarina: Tetranychidae) and Eriophyes madicaginis K. (Eriophyidae): two important phytophagous mites recorded for the first time in Greece. Entomol. Hellenica, 5: 3- 6.

Gerson, U. and Weintraub, P.G., 2007. Mites for control of pests in protected cultivation. Pest Management Science, 63: 658- 676.

Henderson, C. F. and Tilton, W. E., 1955. Test with acaricides against the brown wheat mite. $J$. Entomol., 48: 157-161.

Jeppson, L. R., Keifer, H. H. and Baker, E. W., 1975. Mites Injurious to Economic Plants. Univ. of California Press, California, 615 pp.

Karaca, I., 1994. Life table of Citrus red mite, Panonychus citri (McGregor) (Acarina: Tetranychidae) in laboratory conditions. Turkish J. Entomol., 18(2): 65-70.

Kasap, I. and Lu, E. E., 2004. Life history of Euseius scutalis feeding on citrus red mite Panonychus citri at various temperatures. BiolControl, 49: 645-654.

Kasap, 1., 2001. Interactions between the predatory mite, Typhlodromus athiasae Porath and Swirski and its prey. citrus red mite, Panonychus citri (McGregor) (Acarina: Tetranychidae; Phytoseiidae) and development of degree-day models. Ph.D. Thesis, Çukurova University, Institute of Naturel and Applied Sciences, Adana, Turkey, $93 \mathrm{pp}$.

Kasap, 1., Karut, K., Kazak, C. and Sekero glu, E., 1998. Biology and life table of Citrus red mite, Panonychus citri (McGregor) (Acarina: Tetranychidae) on different host plants. IV. European Congress of Entomology, Ceske Budejovice, Czech Republic, 502- 503.

McMurtry, J. A. and Croft, B. A., 1997. Life-styles of Phytoseiid mites and their roles in biological control. Annu. Rev. Entomol., 42: 291- 321.

Nomikou, M., Janssen, A., Schraag, R. and Sabelis, M. W., 2001. Phytoseiid predators as biological control agents for Bemisia tabaci. Exp. Applied Acarol. 25: 271-291.

Nomikou, M., Janssen, A., Schraag, R. and Sabelis, M. W., 2002. Phytoseiid predators suppress populations of Bemicia tabaci on cucumber plants with alternative food. Exp. Applied Acarol., 27: 57-68.

SPSS Inc., 2004. SPSS Base 13.0 User's Guide. SPSS Inc., Chicago, IL.

Uygun N., Karaca, I. and Ulusoy, M. R., 1992. Integrated Pest Management Studies Against Citrus Pests in Turkey. International Symposium on Integrated Pest Management, Izmir. 95- 108.

Zhang, Z. Q., 2003 Mites of greenhouses: identification, biology and control. CABI publishing, Wallingford, UK, $240 \mathrm{pp}$. 